Report

\title{
Role of health systems research in policy, planning, management and decision-making, with reference to Pakistan
}

Khattak Fazli Hakim'

\section{Introduction}

Health systems research is composed of two components: health systems and research. Health systems include the structure of all health outlets, programmes and projects engaged in providing health care to the population of a country. These health outlets include: primary health care facilities such as basic health units and rural health centres; secondary health care facilities such as district hospitals; and tertiary health care facilities. Health systems research relates to health prevention, treatment and promotion within the national health system and is carried out by institutions on the basis of socioeconomic, political and cultural aspects.

This paper is concerned mostly with policy- and decision-making in the public health sector in Pakistan and the role of health research.

\section{Overview of the health system in Pakistan}

\section{Facilities}

The health system in Pakistan consists of public and private sectors. The private sec- tor provides health coverage to $70 \%$ of the population, whereas the public sector provides health services to the remaining $30 \%$ of the population of the country [1]. The health facilities and health personnel of the public health sector in Pakistan for 1993 are shown in Tables 1 and 2 [2]. The population of Pakistan at that time was 123 million.

Table 1 Health facilities in the public sector in Pakistan

\begin{tabular}{|c|c|c|}
\hline Health facility & $\begin{array}{c}\text { Number } \\
\text { (December } \\
1993 \text { ) }\end{array}$ & $\begin{array}{l}\text { Facility per } \\
\text { population }\end{array}$ \\
\hline Hospitals & 796 & - \\
\hline Hospital beds & 76760 & 1 per 1600 \\
\hline $\begin{array}{l}\text { Rural health } \\
\text { centres and } \\
\text { civil hospitals }\end{array}$ & 600 & 1 per 203109 \\
\hline $\begin{array}{l}\text { Basic health } \\
\text { units and subhealth } \\
\text { centres }\end{array}$ & 5203 & 1 per 23578 \\
\hline $\begin{array}{l}\text { Maternity and child } \\
\text { health centres }\end{array}$ & 829 & - \\
\hline Tuberculosis centres & 233 & - \\
\hline
\end{tabular}


Table 2 Health personnel in the public sector in Pakistan

\begin{tabular}{lrl}
$\begin{array}{l}\text { Health } \\
\text { personnel }\end{array}$ & $\begin{array}{c}\text { Number } \\
\text { (December } \\
\text { 1993) }\end{array}$ & $\begin{array}{c}\text { Health } \\
\text { personnel per } \\
\text { population }\end{array}$ \\
\hline Doctors & 52956 & 1 per 2330 \\
Dentists & 2475 & 1 per 49600 \\
Nurses & 21068 & 1 per 5823 \\
Paramedics & 92389 & 1 per 1328 \\
\begin{tabular}{l} 
Traditional birth \\
\multicolumn{1}{c}{ attendants }
\end{tabular} & 75265 & 1 per 1630 \\
Lady health visitors & 3920 & 1 per 31476 \\
\hline
\end{tabular}

The private health sector accounts for nearly two-thirds of all health expenditure. The health facilities available in the private health sector in 1990 were as follows [3]:

General practitioner clinics

21000

Small to medium hospitals

Hospital beds

16000

Dispensaries

Diagnostic laboratories

The medical practitioners working within the private sector consisted of:

General practitioners (tabib) $\quad 36488$

Homeopaths

21341

Local traditional healers (hakim) 537
A summary of the financial side of the public health sector per decade is provided in Table 3.

\section{Policy- and decision-making infrastructure}

The policy-makers and decision-makers in the health sector of Pakistan are Ministers of Health, Secretaries of Health, Planning and Finance Division, Director-General (Health) and Chief of Health. Senior managers include the directors of the different health programmes, such as expanded programme on immunization (EPI), malaria control programme (MCP), acquired immunodeficiency syndrome (AIDS), tuberculosis, leprosy and heads/executives of the medical institutes and tertiary hospitals, deans of faculties and principals of medical colleges.

Under the constitution of Pakistan, health is a provincial issue, and most of the implementation takes place in the provinces through the respective health departments. However, the Federal Government deals with the decisions about health poli$\mathrm{cy}$, formulation of plans and the main primary health care issues such as EPI, MCP, AIDS, drug policy, user charges and health insurance. The provincial decision-making hierarchy is the same but the bottom level is narrower and includes: divisional directors,

\begin{tabular}{lccc}
\hline \multicolumn{2}{l}{ Table 3 Expenditure on the public health sector by decade } \\
\hline Period & $\begin{array}{c}\text { Development } \\
\text { expenditure } \\
\text { (million Pakistani rupees) }\end{array}$ & $\begin{array}{c}\text { Non-development } \\
\text { expenditure } \\
\text { (million Pakistani rupees) }\end{array}$ & $\begin{array}{c}\text { Total } \\
\text { (million Pakistani rupees) }\end{array}$ \\
\hline 1963 & 35 & 80 & 115 \\
1973 & 176 & 210 & 386 \\
1983 & 1526 & 1564 & 3090 \\
1993 & 2875 & 7680 & 10555 \\
\hline
\end{tabular}

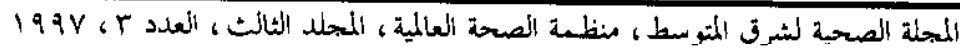


project directors, principals of medical colleges and training schools for medical technicians, nurses and lady health visitors. In addition, planning and finance departments play an important role in decision-making. The personnel within the three-tier system of decision- and policy-making have different backgrounds. For example, a minister is a political person, a secretary is a senior bureaucrat and the Director-General is a medical doctor or a technical person. There is no uniformity in the education, training and profession in the three tiers. It is, therefore, considered that valid information and analysis from health systems research will create uniformity in understanding of the issues under consideration, and provide the necessary background for decision-making and its effective implementation.

\section{Health systems research}

Decision-making in the health sector takes place at the macro level whereas implementation takes place in the regions, going down to the village level through different stages. Health policy is the responsibility of the Federal Ministry of Health with the assistance of the attached health departments. There is a risk of neglect of community interest or a lack of understanding of the problems at the grass-roots level in the existing system of policy-making. In order to achieve a balanced approach, access to the community is required so as to understand the basic problems and needs, and then to design the necessary strategy to solve the problems to be reflected in the health policy of the country. The problems should therefore be studied at the micro level in order to understand the real requirements of the entire population.

The main objective of health systems research is to bring about improvement in the health of the people by increasing the effectiveness and efficiency of the health care system. This is related to the organizational structure of the health care system and the population and their mutual interaction. Therefore, continuous identification of problems and evaluation of the existing health systems are required. Hence, compilation and analysis of facts and figures which facilitate the development of a strategy for the future to meet shortcomings are the identifiable results of the research which will ultimately improve the efficiency as well as the effectiveness of the health systems.

In Pakistan, the research can be initiated on the basis of the available data on the financial and physical position of the health sector. This requires identification of those factors which are hurdles to the improvement of the health system. Although the total health sector budget has increased many fold, and has consequently led to an increase in the number of health facilities and health personnel, the quality of the care has not improved, nor has health care been provided to the entire population. All these factors, once identified, will be helpful in meeting the shortcomings in the future, and will enhance the effectiveness and efficiency of the health systems through improved allocation of resources and equal distribution among preventive, promotive and curative health care.

Improvement of the health care system of the country through health systems research involves a variety of disciplines so that adequate information can be given to decision-makers in a systematic way before they make their decisions. Social, cultural, demographic, economic and political aspects of the issues to be resolved must be considered. The actual research will depend upon the precise nature of the problems, and will require the skills of 
biomedical scientists, sociologists, epidemiologists, demographers, economists, and political, organization and management scientists. However, ensuring the availability of all disciplines and their agreed working conditions will not be an easy task. Furthermore, health systems research is dependent upon the existing infrastructure of research and management. These are important factors but unfortunately the infrastructure in Pakistan is weak and unable to cope with the problems faced by the health sector and its research needs. However, the need has been recognized and it is anticipated that improvements will be made with time. Management does exist but the activities are not research based and not regularly maintained. Decisions are mostly based on out-dated and incomplete information.

Development of the health sector in developing countries depends upon better use of existing resources, whereas health achievement is a combination of various factors of development, such as the extent of the problems, disease patterns, health needs of the population and availability of resources. For example, in Pakistan, the private sector, being a major provider of health services, needs reforms in the form of regulations to ensure the provision of quality care. On the other hand, increase in resources and mobilization in the country requires research to determine the starting point and match the resources with the requirements. The research and analysis should be conducted by assessing: what is; what ought to be; how is/was; how ought to be: and when to be. When this analysis is carried out, various sectors and professionals are involved such as economists, medical personnel, epidemiologists, biostatistians, planners, and sociologists. It is also important not to depend on one or two factors only but to make a realistic analysis of the variables involved which can provide better assistance to health systems research in determining the ultimate variables. In this regard, a Norwegian author commented:

Thus health systems research studies a vast array of possibilities for action. It tries to establish rational uses of medical knowledge and technology, evaluate methods of investigation and treatment, and develop methods for maintaining high quality. It aims to induce logical thought and action on these matters in the health sector and among the public at large [4].

In Pakistan, health systems research has the potential to play an important role in the achievement of health for all by the year 2000 . Decline in the incidence and impact of infectious diseases and awareness of chronic diseases have raised the public's expectations of the health system. However, only a small portion of the gross national product $(0.74 \%)$ is spent on health in the public sector. Low economic and high population growth and demand for resources by other sectors have left little prospect of increasing the budget for the health sector. In this situation, the improvement can only be achieved through greater efficiency, which includes data collection on the inputs and outputs of the health sector, which will provide feedback for planning, implementation, monitoring, evaluation and strengthening of concerned management and administration. As the goals of health systems research are related to the effectiveness, efficiency and cost reduction in the health sector, the economic forces of today are, in fact, of great assistance for encouraging efficiency, cost reduction and effectiveness. 


\section{Health research and health for all}

Pakistan has been following a plan of action to achieve the goals of health for all by the year 2000 through the establishment and improvement of the primary health care network. This includes providing medical equipment, staff and medicine to the primary health care facilities through enhanced allocation, skill development of staff in the outlets and employment of lady health workers in the country. Assessment of the present progress of the primary health care facilities for the sake of improvement in the future is of considerable importance.

Some of the most important indicators for measuring the progress of health for all are as follows [5].

- Health pollcy indicators. These include resource allocation, degree of equity of distribution of resources, community involvement, degree of decentralization in decision-making and organizational framework, and the managerial process.

- Indicators of the provision of health care. These include progress in availability, accessibility and use of the health care services and the quality of care. They should be related to the specific types of services that the national health strategy aims at providing.

- Health status indicators. These include changes and trends in the health status of the population.

- Social and economic indicators. These include demographic and economic trends, income distribution, education, housing and food availability.

Many countries still lack reliable information support for measuring their progress towards health for all. The information is collected at various levels but is not systematically processed, analysed and utilized. Most countries have many potential sources of data which are capable of providing the information required for monitoring and evaluating their national strategies, such as: vital events registers; population and housing censuses; routine health services records; epidemiological surveillance data; sample surveys; and disease registers. However, lack of coordinating mechanisms in collection and processing of information by different sectors not only makes the process very difficult, but also restricts the possibility of utilization of the available information.

Above all, a positive attitude and a genuine desire to measure progress towards health for all, particularly at the policy- and decision-making level, are basic requirements. Information should be perceived as a tool for decision-making and policy reorientation. The available information needs to be converted and presented in such a way that it can be used by policy- and decision-makers, by managers and by the community itself to assess how much progress is being made, to identify areas where changes are needed, and to specify actions that should be taken to bring about such changes. In this way, monitoring and evaluation will promote learning from experience, and will improve both current activities and future planning, and guide the allocation of human and financial resources in order to achieve equity in health which is the essence of the goal of health for all.

\section{Health policy and research}

The health policies are based on objectives and provide guidelines for the achievement of certain targets in the health sector. As research provides hasic information for the 
policy-making process, it is important that the research should have close correlation with the health policies of the country.

Research unrelated to health policies means research that drifts from rational priorities, and policies unlinked to research mean policies unsupported by critical inquiry and evaluation. Both ways of stating this fundamental deficiency of linkages between health policy and research are potentially disastrous in terms of the health programme development that meets true health needs in equitable and cost effective ways. It is probably no exaggeration to say that when research and policy are not effectively linked, a nation is seriously at risk of health development failure, or at least of underutilized services [6].

It is unfortunate that an effective research mechanism and adequately equipped organization for that purpose has not yet been established in Pakistan. Absence of research creates more complications in the process of decision-making. All these shortcomings originate from the unknown status of the research and the fact that it is not given due importance by policy-makers. Pakistan is currently implementing its Eighth Five-year Plan. Resource allocations from the First to the Eighth Plans are given in Table 4 [7]. There is always a meagre allocation for health research in the plans for the country. It is interesting to note that none of the plans prepared so far were based on research within the country. Furthermore, in all the plans, health targets and indicators have been set at the levels of other regional countries without comparing resources. The absence of a research-based approach to allocating resources in line with the targets ultimately ercates more problems. The decision-makers are provided with incomplete feedback which results in a gap between targets and achievements. An example from the current five-year plan illustrates the problem. The infant mortality rate for 1993 was taken as 86 per 1000 live births. In the Eighth Five-year Plan, the target is to reduce this rate to 65 per 1000 live births by 1998 . The infant mortality rate in the country is reported to be 95 per 1000 live births. There is an open question of how to bring down the infant mortality rate by 21 points during the five years of the plan. Are there sufficient resources, i.e. funds, personnel, and other infrastructure available to achieve this target? What was the basis for calculating all these variables? Were these variables based on past trends, and do they provide consolidated ground for the policy-makers to approve the same targets? Were there adequate data available to support the targets and achievements? Most of the questions have no answer because of the absence of health systems research in the country.

The health sector should be seen as a service organization. Tasks, resources, ways of functioning and results should be analysed. It is the job of health systems research to examine the issues in the health sector and make recommendations to the agency concerned with implementation. The results must be passed on to policymakers and health personnel with a view to bringing about improvements. The best way to carry out the research is to cooperate with clinical research workers within the health services system. Clinical research aims at evaluating diagnostic and therapeutic methods through controlled trials. The health sector has a clear responsibility to check continually the quality and efficiency of its services. Unfortunately, clinical personnel rarely have time to reflect on the way in which resources are allocated. Not 


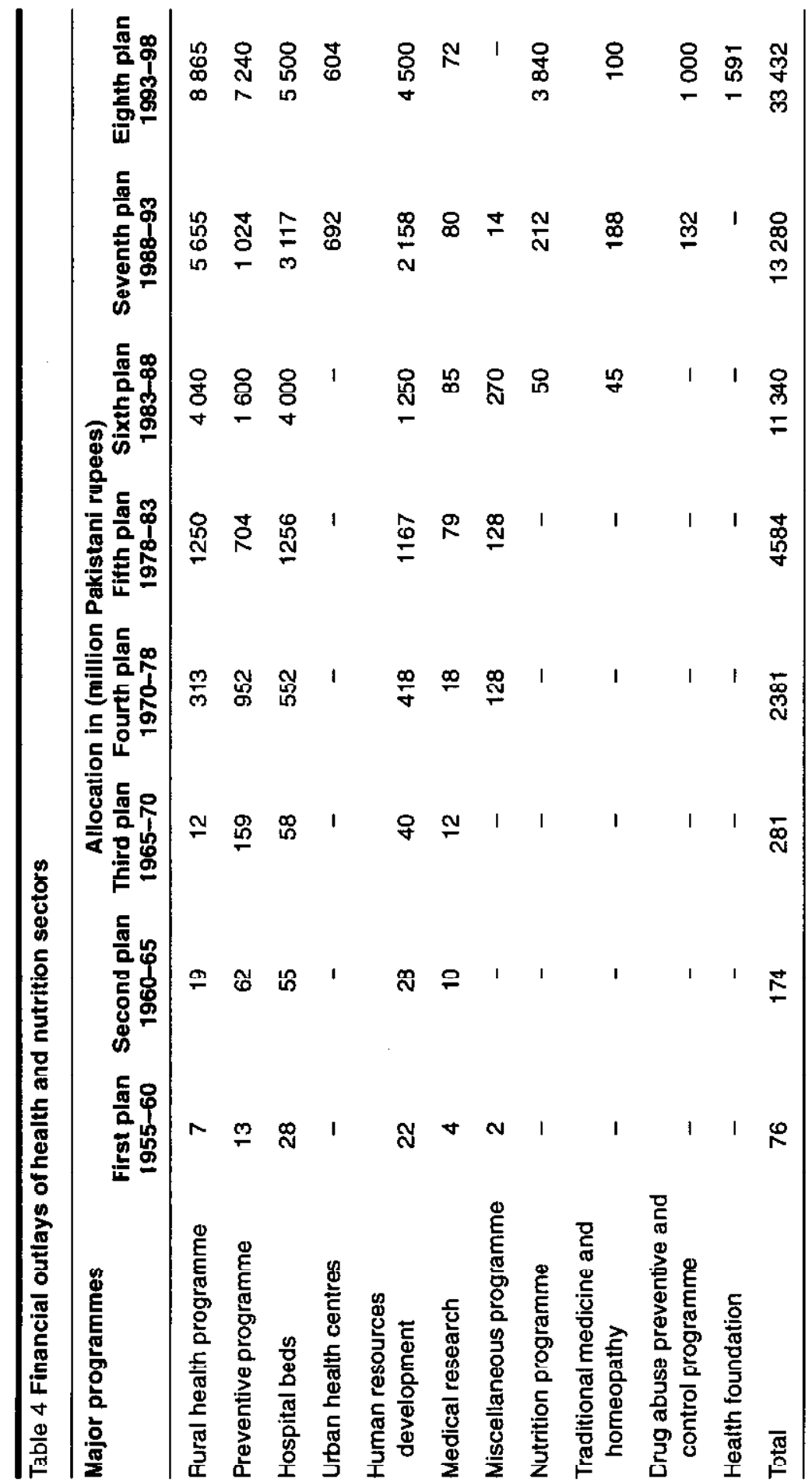


surprisingly, there are regional differences in clinical style which are far greater than can be explained by medical science, and they undoubtedly have important medical and economic implications.

It is important to understand the wide limits within which both patients and health personnel act on a basis of intuition and incomplete knowledge. There are immense variations in the use of resources and in medical outcomes, often to the detriment of efficiency.

As the rate of economic growth decreases, striking the balance referred to earlier becomes more difficult. A number of questions call for research. What, for instance, are the effects of reimbursement systems? Does the new systenl of block grants mliake local authorities set their priorities differently from the way they did when they received earmarked grants or the partial refunding of expenses for tasks specified by the central government? Health systems research should provide insight into how organizational structures and decisionmaking systems influence the capability of central and local authorttes to run the health services according to plan and schedule. It has been argued that reduced economic growth makes it impossible to channel more money into such research, but the realistic view indicates the opposile: slower economic growth means that there is a greater need for critical evaluation of the way scarce resources are spent.

\section{Medical research in Pakistan}

Medical research was considered an important factor and was included in the Sixth Five-year Plan of Pakistan for 1983-88. It was intended to establish a National Clinical Research Institute to conduct research on national health problems and provide support to programmes of primary health care. Other proposed improvements were:

- establishment of research centres in the remaining teaching institutions of the country;

- strengthening of the research component in institutes where potential for medical research already existed;

- creation of a cadre of medical research workers with an appropriate career structure;

- augmentation of health services research with involvement of planning and executing agencies and academia.

An amount of 85 million Pakistani rupees was earmarked for medical research for 198388 , but the results were not encouraging and the targets were not achieved. Little progress was made during the Seventh Five-year plan (1988-93) either. However, the current Eighth Five-year Plan (1993-98) provides a base for health rescarch through a health information system. In addition, a programme of health research costing 70 million Pakistani rupees is being impiemented with the assistance of the World Bank. The programme aims to establish a mechanism for providing health systems research to meet the needs of policy-makers, planners, and health managers for decision-making for long-term investment in the health sector.

\section{Medical and health services research}

The national health policy puts emphasis on the development and use of appropriate health technology through the scientific, technical and managerial resources available within the country. The subcommittee of the Advisory Committee on Health Research in its report published by the World

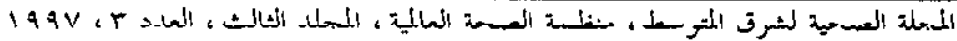


Health Organization (WHO) in 1986 on Health Research Strategy pointed out that,

Our analysis suggests that the success of health for all, particularly the achievement of a minimum standard of health, depends largely on the solution of problems of the health systems. But the range of possible problems is so wide in the field that it is particularly important that research should be goaloriented [8].

The report also stated that the first priority for WHO should be to encourage and assist research which will raise the standard of health in developing countries and in certain deprived subgroups of industrialized countries. The steps needed are well known and the research required is essentially of the health systems type.

The main goal of health systems research is to assist in the provision of better care with wider coverage of the population and at the minimum possible cost. It can do this by providing answers to questions about the functioning of health care systems, and options for remedial action in relation to problems in health care. It is, therefore, a powerful method which should be of use to policy-makers, managers of services and those working in the health care system. Experience shows that as soon as one problem is solved, others arise, so that health systems research is a continuous activity that should be an integral part of the general process of health care. Health systems research is essentially linked to decision-making and concerned with solving problems of high priority.

If health systems research is potentially so valuable, why is it not more widely used? The reasons seem to be many and they include, firstly, a lack of awareness of the value of health systems research by senior policy-makers, so that they fail to sup- port efforts to develop and use the method. Secondly, service managers are generally unfamiliar with health systems research, and do not understand how they can use it to help solve the problems encountered in their duties. In common with other research, health systems research is seen as an academic activity for which managers have no time or resources. Finally, there are few research workers trained and experienced in health systems research and interested in pursuing this type of research rather than laboratory or clinical research.

There is ambivalence about depending on clinical and laboratory research for proper decision- and policy-making purposes. This might not be directly related to the decision-makers and health managers. The vital aspect of clinical and laboratory research is confirmation of the existence of diseases which allows a strategy to be formulated accordingly. It is therefore necessary to encourage clinical and laboratory research within the gencral health systems research. It is argued that clinical and laboratory research is also part of the health system and interrelated with the overall research of the services.

In Pakistan, $0.2 \%$ of the gross national product is allocated to research. The public sector is the major funding agency for research in the health sector, e.g. Pakistan Medical Research Council, National Institute of Health, Islamabad, and medical institutes like the Agha Khan University of Health Sciences in the private sector. There is a vital need to improve the funding position of research through seeking alternative resources, such as from private organizations. Health research has been largely neglected in the past for the following reasons: neglect by the pollcy- and decision-makers; inadequate infrastructure and lack of other required facilities; lack of trained personnel; and low funding. These 
have been major obstacles to successful health research in the country.

\section{Conclusion}

It is through research that new ideas and methodologies are discovered, introduced, developed, and implemented in the system. It leads to more efficient systems and benefits the population through improved health services. Research seeks out more refined approaches to manage and develop new and improved health services and makes them accessible to and affordable by the population.

Pakistan is at the embryonic stage in terms of health research. In view of the importance of health research, attempts have been made at different times to encourage health systems research but they did not succeed because of various obstacles. Some of the obstacles and problems have been identified and solutions have been proposed to establish and strengthen health systems research in the country. Some of the problems related to health systems research are as follows:

- A strong foundation of health research is absent.

- The precise definition and applicability of health systems research have not been identified or have been intentionally neglected.

- Decisions are made on the basis of incomplete data and information.

- Patronization of the existing network of health research is lacking.

- Coordination between public and private health sectors regarding health research is lacking.

- The management capabilities of health managers in the understanding and im- plementation of the output of health research are weak.

- Response from the users and customers of health research is lacking.

- There is poor feedback from the administration of primary health care facilities to confirm the sectoral achievement in the health for all approach and to provide a base for health research.

- A research base for health planning and management is absent.

- Coordination between the research organization and academic institutes, colleges and universities is lacking.

- There is low allocation or absence of resources for health research.

Sulutions to the above problems are outlined below.

- The infrastructure for research should be established in provincial health departments with the collaboration of Pakistan Medical Research Council centres. The personnel should be trained for the purpose and deployed with special incentives.

- Policy- and decision-makers, planners and managers need to understand health research and recognize its importance. Orientation workshops are a great help to introduce health systems research and illustrate its importance to the planners, policy-makers and health managers. The Health Services Academy of the Ministry of Health and the Pakistan Medical Research Council could be the forum where regular interaction and coordination could be organized for policy-makers and health managers.

- A study on the resources spent on the health sector since independence of the country compared with achievements, and identification of the real bottlenecks will help convince the authorities

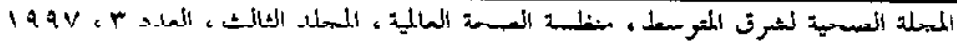


of the need for establishing a strong network of health research in the country.

- There are no incentives for the personnel engaged in health research. A package of financial and social incentives will encourage researchers to work with dedication for the benefit of the population.

- Health plans and policies are not based on the results of reliable health research. A panel of health researchers should be established to provide feedback for policy-makers and planners. The Ministry of Health could easily initiate the proposal and establish such a forum.

- The respective departments of colleges, universities and institutes should be uti- lized for conducting studies and evaluating different health programmes. This will strengthen health research within academic institutions.

- Allocation of funds for health research and should be increased to the required level in the public sector. The private sector should be encouraged to contribute towards health research. This will also establish coordination between the public and private sectors.

Health systems research aims to discover new ideas for the benefit of the people. It is time to introduce and implement the strategy of national objectives of health through a well established system of health research.

\section{References}

1. Health and Nutrition. Eighth Development Plan 1993-98. Planning Commission, Islamabad, Pakistan.

2. Economic survey of Pakistan, 1993. Islamabad, Economic Affair's Division, 1993.

3. Health facilities census, 1990. Islamabad, Federal Bureau of Statistics, 1991.

4. Health systems research in action. Geneva, World Health Organization, 1988 (unpubllshed document WHO/ SHS/HSR/88.1; available on request from the Division of Strengthening of Health Services, World Hoalth Organization, $\mathrm{CH}-1211$ Geneva 27, Switzerland).

5. Report on health research in Pakistan. Karachi, Aga Knan University, 1991.
6. Bashir M. Linkages between health policy and research. Karachi, Conference on Health Research in Pakistan, March 1991.

7. Five-Year Development Plans, 1955-60 to 1993-98. Planning Commission of Pakistan, Islamabad.

8. Health research strategy for health for all by the year 2000. Report of the subcommittee of the Advisory Committee of Health Research. Geneva, World Health Organization, 1986 (unpublished document WHO/RPD/ACHR(HRS)/86; available on request from the Office of Research Promotion and Development, World Health Organization, $\mathrm{CH}-1211$ Geneva 27, Switzerland). 